\title{
Sutureless, Glueless, Scleral Fixation of Single-Piece and Toric Intraocular Lens: A Novel Technique
}

\author{
Aditya Kelkar Rachana Shah Jai Kelkar Shreekant Kelkar Ekta Arora
}

National Institute of Opthalmology, Pune, India

\section{Key Words}

Spherophakia · Aphakia · Scleral-fixated intraocular lens · Sutureless · Single-piece toric intraocular lens

\begin{abstract}
Sutureless, glueless, scleral fixation of an intraocular lens is a known technique of fixing a lens in the scleral pockets. However, this technique is applied to single-piece and toric lenses instead of 3-piece lenses, allowing the advantage of the use of premium lenses in patients with poor capsular support. Favourable results without complications of pigment dispersion, iris transillumination defects, dysphotopsia, elevated intraocular pressure, intraocular hemorrhage and cystoid macular edema with a well-centered, stable intraocular lens have been observed in the 3-month postoperative period in both cases.

(c) 2015 S. Karger AG, Basel
\end{abstract}

\section{Introduction}

The various options for stable intraocular lens (IOL) implantation in cases with poor capsular support include anterior-chamber IOL, iris-fixated IOL, glued IOL and scleralfixated IOL.

\section{Case Report}

Case 1

A 45-year-old female presented to the outpatient department with a history of gradual decrease in vision in both eyes since childhood, which had become even worse during the

KARGER 125/s $\quad \begin{aligned} & \text { Dr. Aditya Kelkar } \\ & \text { National institute of Opthalmology } \\ & 1187 / 30, \text { off Ghole Road, Near Phule Museum } \\ & \text { Shivajinagar, Pune 411005 (India) } \\ & \text { E-Mail adityapune4@gmail.com }\end{aligned}$


Kelkar et al.: Sutureless, Glueless, Scleral Fixation of Single-Piece and Toric Intraocular Lens: A Novel Technique

last 6 months. The patient was a known case of bilateral isolated spherophakia who had previously undergone Nd:YAG peripheral iridectomy in both eyes and was maintained on dorzolamide eye drops.

On examination, her best corrected visual acuity was finger counting at $2 \mathrm{~m}$ in the right eye and 6/18 in the left eye. Her intraocular pressure (IOP) was $11 \mathrm{~mm}$ Hg in both eyes. Anterior-segment evaluation suggested bilateral spherophakia with patent iridectomy and shallow anterior chamber in both eyes and nuclear sclerosis grade II in the right eye and grade I in the left eye. Fundus examination of both eyes was within normal limits (fig. 1).

Her IOL power as calculated with autokeratometry and manual A-scan immersion method was +32.00 dioptres. After discussing various treatment options available with the patient, written informed consent was obtained, and right-eye cataract extraction with a scleral-fixated single-piece IOL, in view of poor capsular support, followed later by the left eye, was planned.

\section{Case 2}

A 60-year-old male was referred from elsewhere for surgical correction of aphakia. He had a past history of right-eye cataract extraction, which had been performed elsewhere 10 years earlier. On examination, his visual acuity in the right eye was finger counting at 2 meters, which improved to $6 / 18$ with $+14.00 /-2.50$ at $80^{\circ}$. His left-eye visual acuity was $6 / 9$ unaided. Anterior-segment evaluation revealed aphakia with no capsular support in the right eye and pseudophakia in the left eye. IOP in both eyes was $14 \mathrm{~mm} \mathrm{Hg}$. Fundus examination of both eyes was within normal limits.

Pros and cons of various options to combat uniocular aphakia - nonsurgical (spectacles, contact lenses) and surgical (secondary IOL implantation) - were discussed with the patient. Written informed consent was obtained. Scleral-fixated toric IOL implantation was planned in view of correcting the astigmatism (fig. 2).

\section{Method}

Case 1

The procedure was done under peribulbar anaesthesia. All aseptic precautions were followed. Linear partial-thickness scleral cuts were made $2 \mathrm{~mm}$ in size perpendicular to the limbus at $0^{\circ}$ and $180^{\circ}$ after minimal conjunctival dissection. Scleral pockets of $1.8 \mathrm{~mm}$, open at only one end, were fashioned with keratome, parallel to the limbus, starting from these marks and running in opposite directions (fig. 3).

Superior conjunctival peritomy followed by a $5-\mathrm{mm}$ scleral tunnel centering at $90^{\circ}$ was done. The nucleus was delivered through viscoexpression. Thorough anterior vitrectomy was done. The anterior chamber was formed with viscoelastic material.

A single-piece Tecnis ${ }^{\circledR}$ lens was placed first in the anterior chamber. A 20 -gauge microvitreoretinal blade was used to make 2 vertically oblique sclerotomies $1.5 \mathrm{~mm}$ behind the limbus at the 2 marked points. A 23-gauge end-gripping intravitreal forceps was passed through the sclerotomy, and the haptic was passed on to the forceps using another similar forceps. The procedure was repeated on the other side, and both haptics were externalized (fig. 4). The haptics were then grasped and inserted into the respective scleral pockets with a McPherson forceps (fig. 5). Centration was confirmed. The conjunctiva was closed over the scleral pockets and superior scleral tunnel. 
Kelkar et al.: Sutureless, Glueless, Scleral Fixation of Single-Piece and Toric Intraocular Lens: A Novel Technique

Case 2

A single-piece Tecnis toric IOL was to be implanted in the axis of $176^{\circ}$ (fig. 2). Linear partial-thickness scleral cuts were made $2 \mathrm{~mm}$ in size perpendicular to the limbus at $176^{\circ}$ and corresponding ones diametrically opposite after minimal conjunctival dissection.

Scleral pockets and sclerotomies were done as described above. A 2.2-mm triplanar clear corneal incision was made at $135^{\circ}$. The anterior chamber was formed with viscoelastic material. A single-piece Tecnis toric foldable implant was inserted into the anterior chamber and gently rotated in the premarked axis. The rest of the procedure was completed as described above (fig. 6).

\section{Results}

Both patients have been followed up for the last 3 months with stable, well-centered lenses.

\section{Case 1}

Unaided visual acuity in the right eye was $6 / 24$ on day 1 , which improved to $6 / 12$ after 2 weeks. Further improvement was not expected due to possible amblyopia. IOP was $12 \mathrm{~mm}$ $\mathrm{Hg}$ on day 1, and the patient was weaned off of antiglaucoma medications 1 week after surgery. She maintained an IOP of $13 \mathrm{~mm} \mathrm{Hg} 3$ months after surgery.

Case 2

Right-eye visual acuity improved to $6 / 36$ on the first postoperative day, which further improved to $6 / 9$ unaided and $6 / 6$ with $-0.5 /-0.25$ at $80^{\circ} 2$ weeks later.

\section{Discussion}

Scleral-sutured IOLs have been popular in the past; however, to avoid the intraoperative and postoperative suture-related problems, Gabor and Pavlidis [1] developed a sutureless technique for sulcus fixation of posterior-chamber IOL using permanent incarceration of the haptics in a scleral tunnel parallel to the limbus. This method offers postoperative axial stability of the IOL while avoiding suture-related problems.

In a scleral-fixated IOL suspended with the suture, there is more pseudophakodonesis, and this may lead to posterior-segment complications in the long term [2]. However, no significant retinal problems are seen with a sutureless scleral fixation technique, potentially because a large part of the haptic is buried in scleral tunnels in these techniques, and so the IOL is inherently more stable and less prone to pseudophakodonesis [2].

This technique and its modifications have been widely practiced by various surgeons worldwide. However, its use is restricted to 3-piece IOLs. This case report represents a successful implantation of a single-piece IOL and single-piece toric IOL giving the benefit of use of premium lenses and better refractive outcomes in such patients with poor capsular support. To the best of our knowledge, this is the first reported case of sutureless scleral fixation of a single-piece IOL.

Sulcus fixation of single-piece IOLs is not popular owing to postoperative complications like pigment dispersion, iris transillumination defects, dysphotopsia, elevated IOP, intraocular hemorrhage and cystoid macular edema [3]. This is due to the fact that bulky single-piece haptics are large and thick enough to contact the posterior iris when placed in the sulcus. 
Kelkar et al.: Sutureless, Glueless, Scleral Fixation of Single-Piece and Toric Intraocular Lens: A Novel Technique

Also, the haptics are planar rather than angulated and therefore do not vault the optic posteriorly from the iris [3].

None of the above complications were encountered during the 3-month follow-up. This is probably due to the offset design of the single-piece Tecnis lens and single-piece Tecnis toric IOL. Neither the optics nor haptics come in contact with the iris. In addition, the use of a single-piece instead of a 3-piece design eases externalization and reduces the chances of slippage or breakage of the haptics. The thick stubby haptics block the sclerotomies completely; hence, there is no need for suturing.

\section{Conclusion}

Sutureless scleral fixation of a single-piece IOL and single-piece toric IOL provides a useful alternative in the management of cases with poor capsular support in situations where a 3-piece IOL cannot be used.

\section{Statement of Ethics} kin.

Detailed informed written consent was obtained from the patient and patient's next of

\section{Disclosure Statement}

The authors declare that they have no competing interests, no proprietary interests, and no other disclosures.

\section{References}

1 Gabor SG, Pavlidis MM: Sutureless intrascleral posterior chamber intraocular lens fixation. J Cataract Refract Surg 2007;33:1851-1854.

-2 Prasad S, Grzybowski A: Considerations in the management of aphakia. Indian J Ophthalmol 2015;63:358.

-3 David F, Chang MD, et al: Complications of sulcus placement of single-piece acrylic intraocular lenses.

Recommendations for backup IOL implantation following posterior capsule rupture. J Cataract Refract Surg 2009;35:1445-1458. 


\section{Case Reports in \\ Ophthalmology}

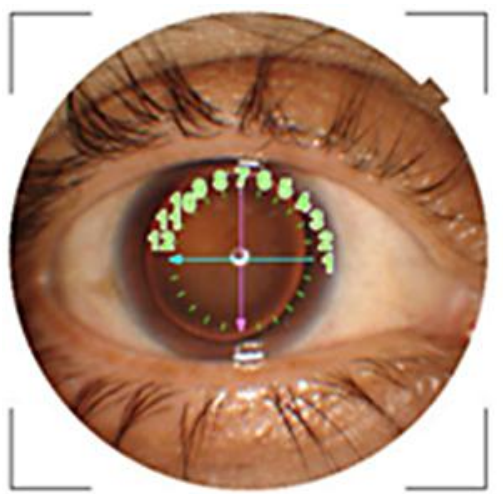

Case Rep Ophthalmol 2015;6:239-245

DOI: $10.1159 / 000437349$

Kelkar et al: Sutureless,

ueless, Scleral Fixation of Single-Piece and Toric Intraocular Lens: A Novel Technique

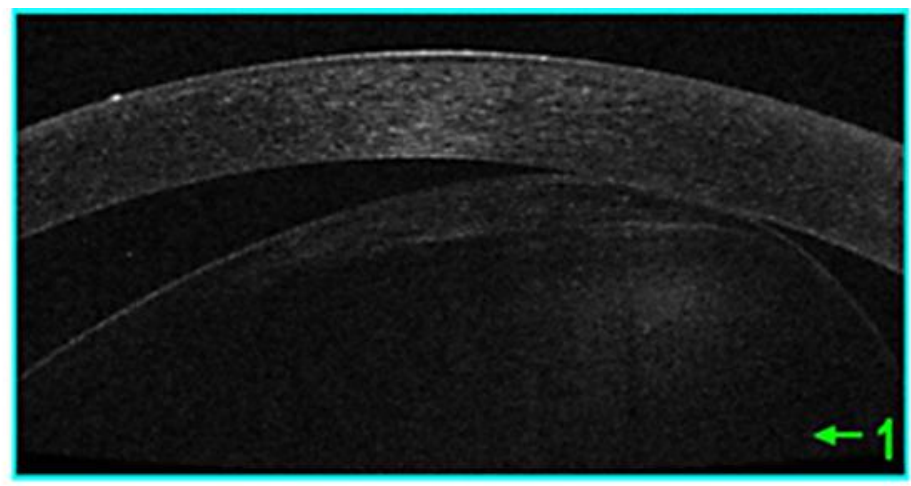

Fig. 1. Preoperative anterior-segment picture and optical coherence tomography.

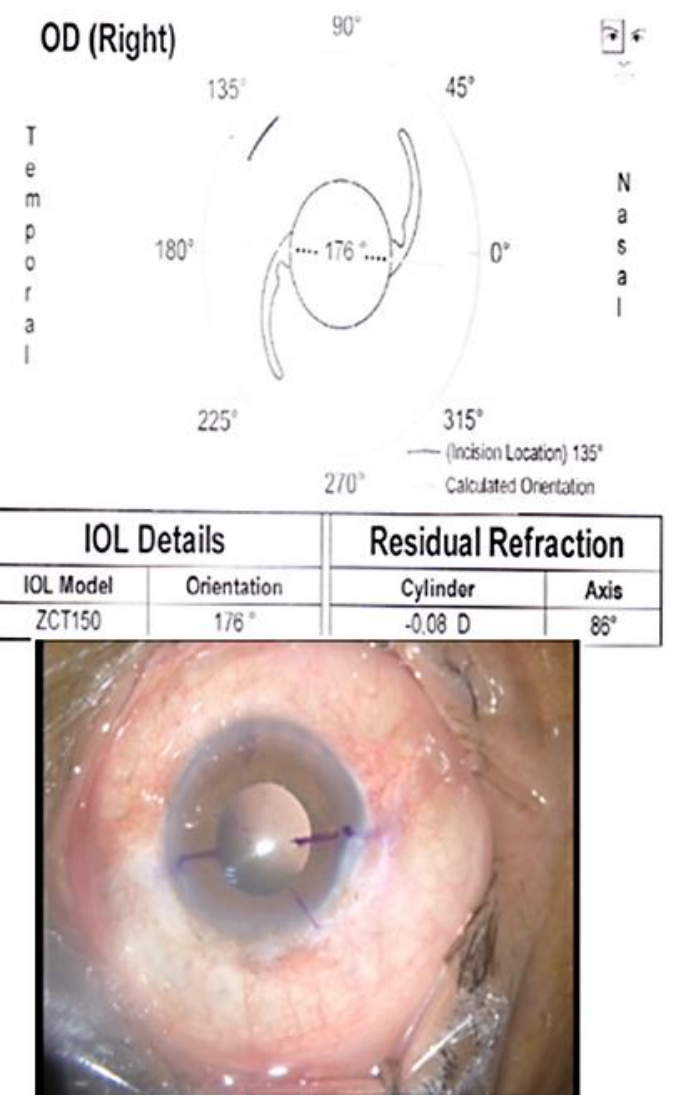

Fig. 2. Marking the axis of the toric IOL. 


\section{Case Reports in \\ Ophthalmology}

\begin{tabular}{l|l}
\hline \multicolumn{2}{l}{ Case Rep Ophthalmol 2015;6:239-245 } \\
\hline DOI: 10.1159/000437349 & $\begin{array}{l}\text { @ 2015 S. Karger AG, Basel } \\
\text { www.karger.com/cop }\end{array}$ \\
\hline
\end{tabular}

Kelkar et al.: Sutureless, Glueless, Scleral Fixation of Single-Piece and Toric Intraocular Lens: A Novel Technique
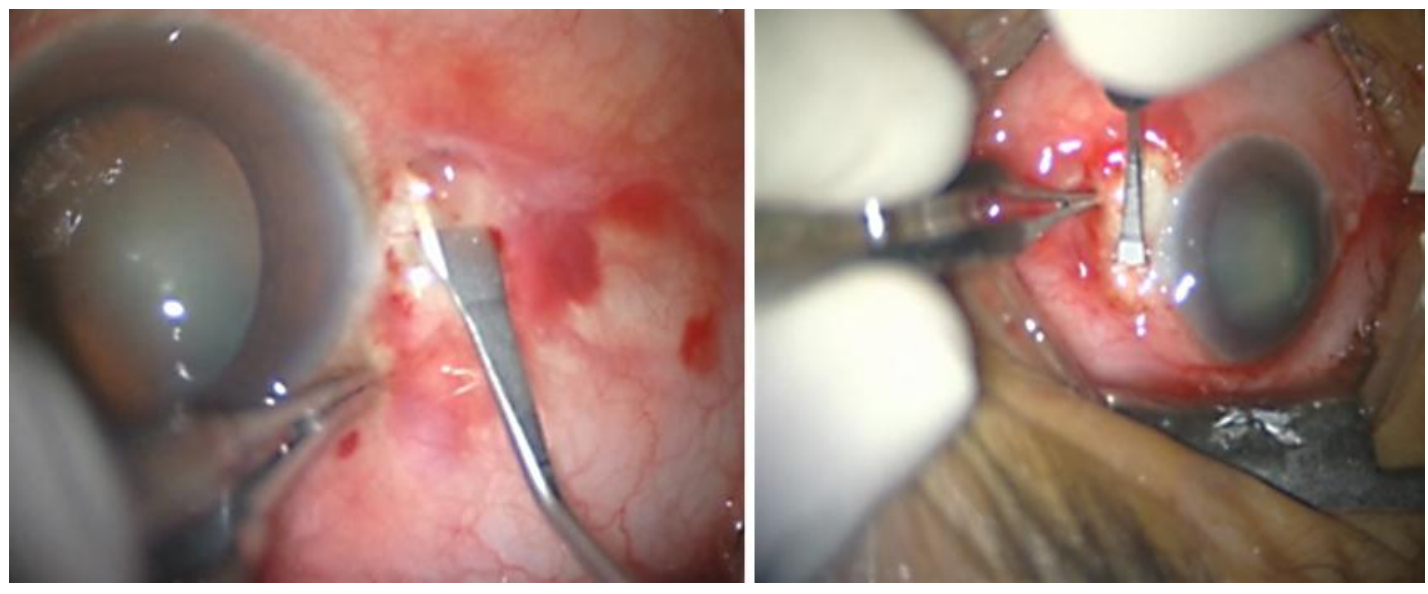

Fig. 3. Scleral pockets (1.8 mm), diametrically opposite.

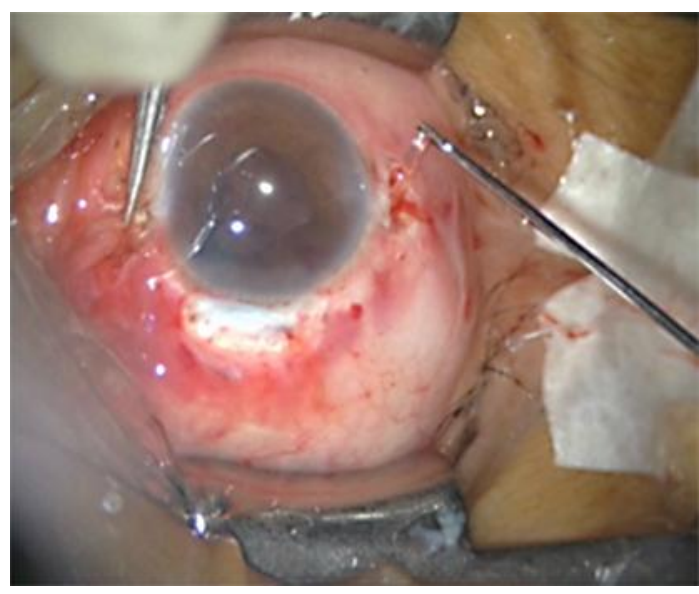

Fig. 4. Haptics externalization.

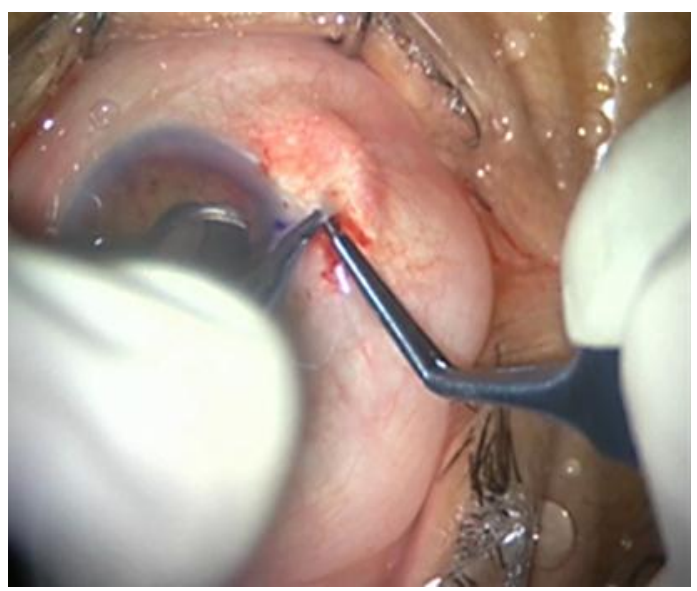

Fig. 5. Haptics tucked. 
Case Reports in

Ophthalmology

Kelkar et al.: Sutureless, Glueless, Scleral Fixation of Single-Piece and Toric Intraocular Lens: A Novel Technique

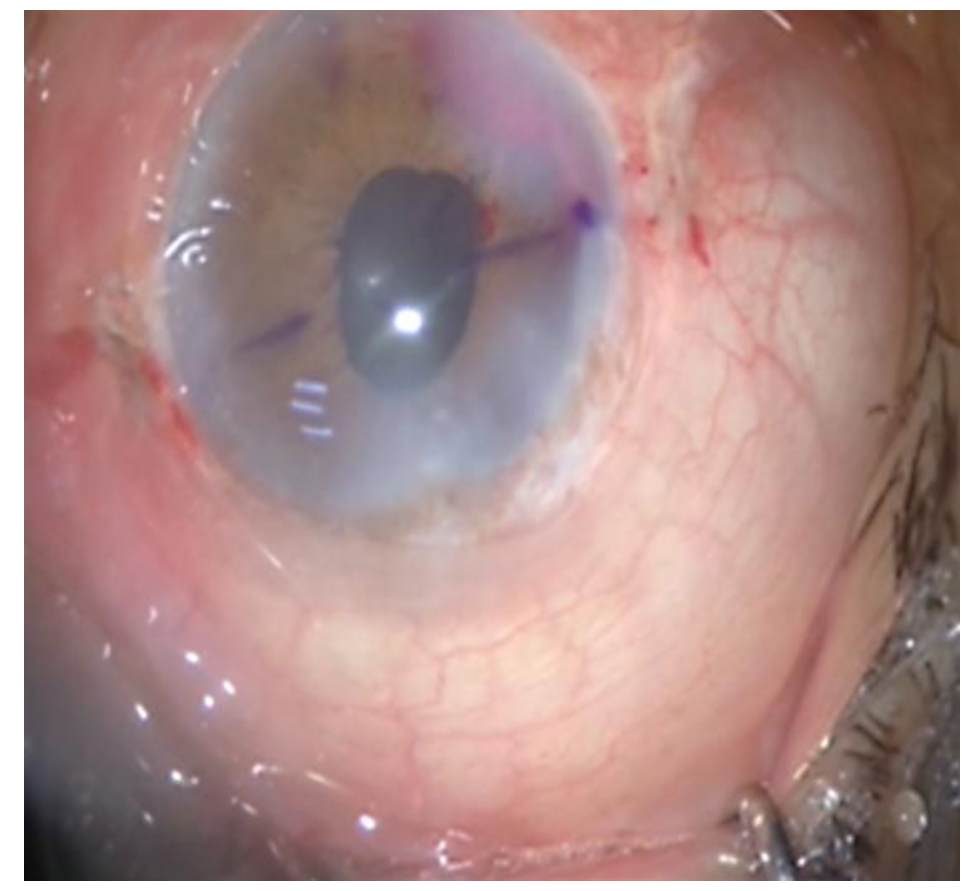

Fig. 6. After conjunctival closure. 